\title{
Otra «letra del espíritu»: citar lo imposible
}

\author{
Julián Santos
}

\section{(2) OpenEdition}

\section{Journals}

Edición electrónica

URL: https://journals.openedition.org/cher/2545

DOI: 10.4000/cher.2545

ISSN: 2803-5992

\section{Editor}

Presses universitaires de Strasbourg

\section{Edición impresa}

Fecha de publicación: 27 junio 2017

Paginación: 35-45

ISBN: 978-2-86820-961-0

ISSN: 1968-035X

\section{Referencia electrónica}

Julián Santos, «Otra «letra del espíritu»: citar lo imposible», reCHERches [En línea], 18 | 2017, Publicado el 01 diciembre 2021, consultado el 16 diciembre 2021. URL: http://journals.openedition.org/cher/ 2545 ; DOI: https://doi.org/10.4000/cher.2545

\section{c) (i) (2)}

Ce(tte) œuvre est mise à disposition selon les termes de la Licence Creative Commons Attribution Pas d'Utilisation Commerciale - Partage dans les Mêmes Conditions 4.0 International. 


\title{
Otra «letra del espíritu»: citar lo imposible
}

\author{
JULIÁN SANTOS*
}

\begin{abstract}
Comienzo esta exposición con un préstamo, con una voz cogida de otro. En este caso la de un querido amigo. Hace meses que esta conferencia le fue asignada y aceptada por él su exposición. Un problema de salud imposibilita hoy su voz y le dificulta al extremo sus movimientos. La testaruda mudez de su garganta le tiene a la espera de que una rehabilitación eficaz devuelva el espíritu a su voz y a sus miembros. Me refiero al profesor Fernando Rampérez para quien estas palabras quieren ser un homenaje de amistad y un reconocimiento de admiración intelectual.

El título de esta conferencia es ya una cita, la del título que él mismo había dado en su tiempo a la organización. Me hubiera gustado haberles leído aquí sus palabras, haber hecho una simple transposición ante ustedes de aquella «Letra del espíritu»; porque este fue el título que él dio a la intervención que debería pronunciar hoy. Pero, al menos en lo que yo sé, esta conferencia no llegó a redactarse. Así pues, el título no era solo el enunciado de un tema sobre el cual el profesor quería hablarles, sino la promesa hecha ante la dirección del congreso y ante los futuros oyentes, un compromiso asumido por su parte: «Hablaré, expondré, la "letra del espíritu". Esa será mi intervención».
\end{abstract}

De este modo, y en la medida en que sus palabras de título se insertan gracias a un entrecomillado en el título de mi conferencia, se trata de una cita, de una cita de algo que no fue nunca escrito ni dejado a la memoria de la letra, una cita de un texto que no existe o que no sabemos si existe, y que enuncia una promesa, su promesa.

A partir de esta premisa el reto que me propongo aquí y ahora ante ustedes es pensar la posibilidad o la imposibilidad de citar una promesa, de tomar prestada también la promesa del otro, de hacer mía una promesa que viene

* Profesor de Estética en la Facultad de filosofía de la Universidad Complutense de Madrid, y profesor en el Centro de estudios internacionales de la fundación José Ortega y Gasset. 
del otro, partiendo, como pueden imaginar, de una imposibilidad: para mí es imposible leerles la «letra del espíritu» de Fernando Rampérez. No cabe más remedio que pronunciar aquí "Otra "letra del espíritu"» Pero quiero mantener la promesa: ¿Es posible citar una promesa? Esta cuestión derivará sin solución de continuidad en esta otra: ¿Cómo citar lo imposible?

Para entrar en esta difícil cuestión deberemos hacer algunos recorridos y formalizar en ellos el carácter acontecimental de la promesa y su relación con la escritura y la textualidad. Una vez expuesto ese carácter de acontecimiento, será necesario ahondar en la categoría de imposibilidad que, como veremos, le está implícita, y cuestionarnos si lo imposible puede ser citado sin perder su carácter de imposibilidad, y si hay transposición de lo imposible, o incluso, si hay en toda transposición, transposición textual en concreto, ya una instancia de imposibilidad.

Para abordar este programa y ese reto que empezaba con la cita de una promesa, será imprescindible, antes que nada y a modo de introducción, comprender algo que le ocurre a la cita: y es que todo recorte de un discurso literario tomado en préstamo, inserto en otro, trasladado a otro, toda cita tomada, todo trozo textual, mantiene siempre una ingobernable inestabilidad en sus bordes, en el marco que le cierra y le contiene. Por decirlo de un modo muy explícito: el texto citado, como le ocurre a toda escritura, comporta un problema de incontinencia. ¿Dónde termina y dónde empieza un texto?, ¿cuáles son sus límites, sus bordes? Esta será la cuestión previa y la primera a considerar.

En un texto siempre hay más de un texto, porque un texto exige siempre un movimiento de remitencia, un incesante movimiento que asimismo le constituye. Un texto no puede ser pensado bajo la seguridad del presente: algo que se presenta en su acabamiento o en su completitud. No es algo que se presenta como tal. Decir texto es nombrar una red de instancias referenciales, de huellas, de marcas que siempre remiten a otro de sí, a un fuera de sí, a un otro. De tal forma que el texto no está de acuerdo consigo mismo, no se regula por el principio de identidad ni es idéntico a sí mismo. Comporta siempre un fuera de sí dentro de sí. Contiene en su interior algo que le es exterior.

Esta imparable remitencia no tiene un límite prefijado, lo cual no quiere decir, como es obvio, que una cita no tenga límites (de ahí las comillas de cada principio y en cada terminación citacional), sino que ese límite textual opera de un modo complejo, a saber: también como dispositivo de implicación, de implantación, de incrustación, en otro texto. Esas comillas son, literalmente, la marca de la alteridad, la marca del otro, la señal de lo que viene del otro, del otro lado también de las comillas. Esto quiere decir que una parte, un trozo de cualquier escrito, siempre puede cambiar de contexto; porque su contexto no está saturado ni es saturable. Aquello que bordea el texto es asimismo el reclamo de su desbordamiento. Las comillas son la marca de su desmembramiento, de su movilidad estructural: destacan un pedazo de texto, lo señalan, al tiempo que nos dicen que todo texto es fraccionable, divisible, y en ese sentido, destacable, 
separable. Las comillas son la señal gráfica de lo transportable del texto, de su capacidad de jugar en cualquier campo.

¿Se imaginan el juego que pueden dar aquellas palabras que hemos pronunciado más arriba si son trasladadas a un reclamo publicitario de procesadores de texto o de continentes virtuales de información, de dispositivos de memoria?: «toda escritura comporta un problema de incontinencia». Por no hablar de aquella otra «el texto no está de acuerdo consigo mismo».

En este punto nos citamos otra vez con Fernando Rampérez. En este caso con una cita de su libro A destiempo. Sobre Proust, filosofía, literatura y otros relatos. Citamos un párrafo que nos concita en una común manera de mirar la textualidad. Dice así la cita:

Efectivamente, todo es texto, no hay contextos y, si los hay, no son saturables; no es posible la descripción de una experiencia porque la experiencia está ya codificada y automáticamente nos reclama una interpretación. Esa interpretación produce un nuevo texto. El vehículo que nos permite pasar de un texto a otro es la metáfora. Todo consiste, en definitiva, en una inacabable traducción intertextual, una deconstrucción. (Rampérez 2009: 91)

En este párrafo subrayamos tres ideas que pesan de un modo muy evidente. Por un lado la insaturabilidad del contexto: «no hay contextos y, si los hay, no son saturable». Por otro lado, también la imposibilidad de una interpretación acabada y única del referente: «Esa interpretación produce un nuevo texto». Y por último, el movimiento inacabable de una deconstrucción.

Hasta aquí nos hemos limitado a exponer de un modo conciso la noción de texto que Derrida propone, también la reunión de estas ideas con las de Fernando Rampérez. Nos hemos citado a varias bandas, y es preciso avanzar ya unos primeros resultados. Así pues, llevando al límite la operación de esa incontinencia que el texto comporta, podría decirse que eso que llamamos «realidad» tiene ya la estructura de texto. Esta es una afirmación sabida de Derrida y que ahora voy a explicar.

Como decíamos, las comillas son la marca de una alteridad, pero también de la alteridad consigo mismo del texto, de su fraccionabilidad y de su remitencia irrefrenable al otro, la marca del otro en cada cita. Lo importante ahora es comprender que ese o eso otro, no es un este o aquel, no es ningún contexto que viniera a «solucionar» el problema del sentido de un texto. No es un mecanismo de resolución, sino la indeleble herida que atestigua de una falta de completitud en el texto, de una falta en el «en sí»; de una encentadura o corte que impide su reunión en la unidad, también en la unidad del sentido o en la propiedad del sentido. Esa marca lo es, pues, de una impropiedad estructural al texto. Dicho de otro modo: el texto no tiene sentido propio (de ahí el papel de la metáfora, que señalaba el profesor Rampérez).

Digamos que se trata de un encadenamiento, de la incesante formación de cadenas que solo pueden ejercerse merced a la falta de completitud, o lo que viene a ser igual, por la inclusión en el interior de una irreductible exterioridad, 
alteridad, desajuste íntimo. En eso consiste esa alteridad de la que hablábamos: un cierto otro en el texto. De ahí que «esto otro» no sea algo que se presenta, sino una resistencia al presentarse, al hacerse presente, y que al tiempo lleva al texto más allá de sí: remitencia, referencia, paso, transferencia, ferencia (recordemos el verbo latino fero: llevar, también llevar con la palabra, transmitir con ella). Esa alteridad supone un desajuste y también la exigencia de encadenamiento: corte y vínculo (como aquellas comillas, decíamos). Un encadenamiento con otro texto en virtud de aquello que no le clausura, que no le identifica, en virtud de una fractura interna que abre paso al otro, de una ferencia, de una diferencia.

Visto así, un texto no es una simple transcripción de algo que podría llamarse «realidad» y que está fuera del texto. Eso que llamamos exterior al texto, sea una experiencia, un sujeto-autor, un tiempo histórico o geográfico, un contexto cultural, una «realidad» en suma que decimos es «exterior» al texto; pues bien, esa «realidad» se comporta asimismo como un texto, posee la estructura de texto $^{1}$. Todo lo que entendemos que tiene sentido, todo el orden mismo del sentido, implica ya el juego de esos desajustes internos, de esas cadenas y de esos encadenamientos.

Así entonces, un texto no se ve ni refrendado ni referido a un «fuera de texto» que trascendiera a cualquier fórmula escritural o representativa, no remite a ninguna presencia originaria que se alce como origen del sentido y fuera de toda representación, de toda diferencia. Más bien el texto es productor de sentido. Y no puede dejar de hacerlo. Siempre que hay un texto se opera inmediatamente un requerimiento de sentido, una promesa de sentido. Incluso aunque estemos convencidos de que un conjunto de signos «no tienen sentido»-decimos a veces-, buscamos no obstante un sentido a su falta de sentido.

$\mathrm{Y}$ es que todo sentido proviene, pues, de un juego de referencias, de remitencias, de cruces o de tramas. Un texto siempre remite a otro texto y en esa remitencia, en ese desvío de sí, consiste la operación del sentido. Esta es la razón por la cual el sentido de un texto está en todo caso abierto por la alteridad del otro: un texto es ya una cita de otro, viene de otro texto que, a su vez, proviene de otro, de otros, en una remitencia que desborda los límites definidos, designados o asignados a cualquier texto. De ese juego de remitencias, decíamos, surge el sentido.

De aquí una curiosa conclusión: no se puede salir del texto así ampliado, no se puede salir; pero tampoco se puede entrar, puesto que desaloja de continuo, refiere. «Dentro» y "fuera» están ya desestabilizados como categorías, están ya en deconstrucción, diríamos. El texto siempre desaloja, siempre se cita, se cita

1 Citamos a Derrida (1986: 166): «Pero me parece necesario, y he tratado de mostrar por qué, reestructurar este concepto de texto y generalizarlo sin límite, hasta el punto de no poder seguir oponiendo, como se hace normalmente, bien el texto a la palabra, o bien el texto a una realidad -eso que se denomina "realidad no textual"-. Creo que esa realidad también tiene la estructura des texto; lo cual no quiere decir, como me han hecho decir alguna vez, que todo lo real esté simplemente encerrado en un libro». 
con otro y en esa cita con otro se halla una promesa, una promesa de sentido: el provenir del texto como promesa de sentido (como nosotros aquí, citándonos con el amigo ausente, con la «letra del espíritu» del otro).

Dentro de un momento volveremos a esa promesa; ahora permítanme que ahonde un poco más sobre aquella impropiedad del sentido. Y es que no se trata de una incompletitud, como si el sentido de un texto apuntara a una tarea interminable. No es que el sentido de un texto venga dado en un virtual infinito que se demora indefinidamente, haciendo así que todo acto de interpretación sea parcial, si bien no obstante orientado hacia esa totalidad virtual de la que el intérprete se ve falto. Más bien, lo que dice esa impropiedad es que hay una radical falta de sentido en el texto, una interrupción del sentido, un sin-sentido absoluto que resiste al orden del sentido, y por ello a la presencia y al presentarse. El propio Derrida lo ha enunciado muy claramente. Cito: «Un texto permanece además siempre imperceptible. La ley y la regla no se esconden en lo inaccesible de un secreto, simplemente no se entregan nunca, en el presente, a nada que rigurosamente pueda ser denominado una percepción» (Derrida 1975: 93).

Eso significa que en todo texto fondea un no saber, una falta de sentido: que no hay un sentido propio en algún lugar o en ningún ámbito escondido a la espera de su desocultamiento. Ningún sentido propio, en propiedad. Esto hace que cada sentido dado sea siempre "prestado», si bien ese préstamo no significa que sea un «como sí» o un simulacro de sentido: la impropiedad afecta más bien a la noción misma de sentido. Todo sentido, todo sentido dado a un texto, está ya roto, fragmentado de antemano por una falta de sentido, por un salto inventivo. Todo sentido dado se entrelaza con una impropiedad. En todo sentido hay siempre, pues, una instancia metafórica, una impropiedad de base. Y esto precisamente es lo que confiere a la lectura una inseguridad radical. Dicho de otro modo: no hay lectura adecuada, propia, que dijera el sentido del texto. Siempre hay en cada lectura una reescritura, un plus o un suplemento de sentido que añade algo y al tiempo suplanta la falta. Un añadido, un préstamo o una impropiedad, un efecto otro, una alteridad que, sin embargo, ni puede evitarse ni necesariamente entrega al texto a posibilidades nefastas o negativas: esa impropiedad del otro reafirma las posibilidades del texto, lo abre a la promesa de sentido, lo expone a la génesis de sentidos, lo constituye como una operación germinal.

A esta operación germinal que parte asimismo de la imposibilidad del sentido, de la imposibilidad de contar con un sentido dado de antemano, con un origen o un fuera de texto a salvo de la lectura y ajeno por tanto a cualquier interpretación, Derrida la llama «diseminación», es decir, perdida de la simiente, muerte del padre-origen $y$, al tiempo, inseminación, promesa de generación aventurera.

Sé que estamos corriendo un poco, que tal vez vamos demasiado a prisa, y me consta también que estos enunciados traen consigo una cierta sensación de vértigo; por ello seguramente alguien entre ustedes estará pensando algo 
así como: «Entonces, aquí no hay reglas», o «si todo sentido dado al texto es igualmente prestado o simulado, en todo caso, impropio, eso vendría a decir que, todo vale». Esta es la frase más repetida para desprestigiar eso que en la cita de Fernando Rampérez se anunciaba como «deconstrucción».

Sin embargo pensemos un poco más la frase. El hecho de que el sentido del texto, que todo sentido en general, contenga una fragmentación, una impropiedad, no significa que pueda aplicarse de cualquier manera o que pueda ser cualquiera el sentido del texto. Más bien dice que ningún sentido dado puede ser «el sentido» del texto, y que todo sentido comporta algo impropio. O dicho de otro modo, el valor de ese «valer» que determina lo que vale y lo que no vale, el sentido válido y el no validado, dimana de un juego; y es precisamente ese juego lo que confiere valor o validez a este sentido frente a otro. Decir esto «vale» y eso "no vale», significa hacer efectiva una estructura valorativa: académica, judicial, política, estética, etc. Y bien, lo que dice aquella impropiedad es que esa estructura valorativa académica, judicial, política, estética que da valor a este sentido o a aquel otro, saca su posibilidad de dar valor, de inferir un valor (por ejemplo el de verdadero, científico, políticamente correcto o no, etc.) de un juego, de aquel juego de remitencias y referencias, juegos sin referentes fijos, sin referencias ideales a socaire del juego.

Ello no dice que esas valoraciones de sentido no obliguen, o no sancionen, no se impongan, a veces incluso con la violencia de un despotismo o de un autoritarismo institucional sin límites. Pero aun así, lo que aquella impropiedad del sentido dice es que por más que una lectura se imponga y se postule como la más valiosa, su imposición siempre la viene de un préstamo o más bien de una impropiedad en el origen mismo del valor.

Recapitulemos. Un texto es un generador de sentido, y tal instancia productora saca su posibilidad de un corte interno, de una íntima interrupción de sentido, de la implicación de una alteridad, de una venida del otro que no obstante le abre a una remitencia sin fin. Un texto es siempre la contestación de la propiedad y aun, de la propiedad privada. Siempre ofrecido a un otro que asimismo lo constituye. Siempre en la promesa de sentido cuya condición de posibilidad es, precisamente, la imposibilidad de sentido que el texto alberga.

Decíamos hace un momento que hablaríamos de la promesa, porque se trataba de saber si es posible citar una promesa. También vimos que «La letra del espíritu» era la promesa. Por eso tenemos ahora que reflexionar un poco sobre la promesa.

Veamos. La promesa, como también le ocurre al juramento, por ejemplo, son actos de lenguaje que no obstante producen algo en el mundo de los hechos. Su carácter no es simplemente enunciativo, la promesa no habla de algo, sino que por su enunciación misma opera o da lugar a ese algo. Está a caballo, pues, entre el lenguaje y el mundo; es una incursión del lenguaje en el mundo, en el acontecer. De ahí ese nombre que da Austin a este tipo de actos de lenguaje: performativos, o realizativos. 
Una promesa de amor, una promesa de pago, una promesa de fidelidad, son siempre enunciaciones que comportan el compromiso de un porvenir: «prometo amarte», "prometo serte fiel», "prometo pagar», «prometo hablar de la letra del espíritu». La promesa moviliza el porvenir. Pero fíjense, que siguiendo en ello a Derrida, no decimos futuro, sino porvenir. Esto es, la promesa moviliza algo que viene, un movimiento de venida que, por definición, no ha llegado y que pone en el horizonte una inseguridad en su llegada. El porvenir, por definición es incierto. Cuelga un «no se sabe» en el horizonte de su realización. Cuando hablamos de futuro hablamos de algo que espera, de un presente que todavía no se ha presentado, sin embargo cuando hablamos de porvenir hablamos de un horizonte abierto, no cerrado: tal vez, quizás, puede ser.

Y bien, la promesa no es simplemente el alcance previsible del futuro. Sería ridículo que hoy jueves yo les prometiera que mañana será viernes, o que les prometiera que después de este día vendrá otro. Más bien las promesas movilizan lo inesperado del porvenir; de ahí la promesa bíblica del final de los tiempos, o nuestras promesas más cercanas, como la promesa amorosa o de fidelidad o de pago. Si prometo pagar es porque está en el horizonte de mi acto de promesa el impago, esto es, que algo me impida pagar; o en el horizonte de mi amor algo que, sobrevenido, borre mi amor por ti, un desamor; o la infidelidad. Porque eso ocurre, porque el amor es frágil, voluble, porque la fidelidad es rara, apelo entonces a esa interrupción en el orden de lo previsible cada vez que prometo.

Una promesa da un salto sobre todo eso, y promete lo que no se puede asegurar, lo que no es evidente, lo que puede que no ocurra, lo que ciertamente no está en las manos del que promete: por eso se promete, porque no es asegurable. Ahí está lo que la promesa tiene de promesa: tiene en cuenta una inseguridad radical y salta por encima de ella. Esta inseguridad radical es algo que rompe el tejido de la previsibilidad, el orden estructurado de las causas y los efectos. Rompe cualquier horizonte de anticipación y de espera: lo no previsible, lo que no se ve venir, lo que viene sin verlo venir. Por ejemplo, el que promete sabe que puede morir, que quizás la muerte llegue antes del cumplimiento de la promesa. Puede que la muerte borre mi amor hacia ti, puede que la muerte me impida pagar... Porque no es seguro, porque el horizonte de posibilidad de cumplimiento está roto de antemano, hay promesa. Solo un mortal puede prometer.

La promesa tiene ese carácter de acontecimiento, de lo que ocurre por primera vez, por una sola vez, solo esta vez, singularmente, y lo saca de esa movilización de un cierto imposible. Cada promesa es, en ese sentido, singular. Cada vez que se promete se apela al acontecimiento ${ }^{2}$.

Ahora volvemos a aquella promesa de sentido que hay en el texto, también allí se apela a la imposibilidad. Incluso podríamos decir que en la medida en que esa palabra, «texto», se amplía a todo el campo de lo que tiene sentido, a eso que

2 Para un mayor seguimiento de esta noción en Derrida remitimos a Derrida (2006). 
llamamos realidad, la realidad se encuentra ya abierta, no es dada de una vez por todas. Ello quiere decir que la donación de lo que hay viene marcada por una interrupción de sí o del sí mismo, de todo sí mismo.

¿En qué sentido se interrumpe? No desde luego en el sentido de que deje de darse, no tendría esta afirmación un carácter apocalíptico como aquellas que hablan del fin de la filosofía o el fin del arte, del final de la metafísica, o de las ideologías. Tampoco dice que lo que se da o lo que viene lo haga desde o a partir de una interrupción, de una ausencia o de una retirada, desde una cierta èpokhé del ser, como diría Heidegger, o de un origen escondido, como pensaría una cierta teología negativa; sino que lo que se da, aquello mismo que se da, el darse de lo que se da, no lo hace - vamos a decirlo así- completamente. Se mantiene abierto, roto, encentado (entamé, dice Derrida) ya en el origen, desde el origen. Así pues, no se da totalmente o, no se da "como tal».

Cuanto ocurre, de alguna manera no pasa o no termina de pasar: hay algo que no pasa. Más aun, para que algo tenga sentido, para que algo pase, es preciso que ese algo comporte un cierto no pasar, una aporía, una interrupción, una falta radical en el darse, en la existencia.

Sé que esto podría parecer un simple juego de palabras, una manera más o menos oscura de jugar con el lenguaje, pero es algo más que un simple juego, señala la holgura, el juego pues, de la donación de sentido, y refiere a una donación no clausurada, un imposible en el movimiento mismo de donación de sentido, de lo que pase o que pueda pasar. A eso no designable, no consignable, ça, Derrida lo llama imposibilidad y es ello lo que confiere al acontecimiento, al évenement, a lo que viene, su condición de acontecimiento.

A ese respecto, Derrida viene a decir que lo que da a un acontecimiento su posibilidad, lo que hace que un acontecimiento pueda ser posible, es justamente la imposibilidad inherente al mismo. Pero, ¿cuál es ese orden de posibilidad imposible? ¿Cómo es ese des-orden de lo imposible que abre la posibilidad del acontecimiento? A ello hace referencia una de las definiciones que Derrida ha dado en varias ocasiones de la deconstrucción: «la deconstrucción sería quizá "la experiencia de lo imposible"», dice Derrida (1998: 507).

A veces decimos cuando algo acontece de súbito, cuando algo imprevisible ocurre, «es imposible», «no puede ser», «esto no puede haber ocurrido». A ello atañe aquella definición hipotética de la deconstrucción: «la experiencia de lo imposible».

Maticemos un poco más. No se trata de hacer ver que aquello que parecía imposible ahora es posible, como el hecho de volar, de poner en el cielo un aparato más pesado que el aire, por ejemplo, de hacer volar a un ser humano. Esto hasta no hace demasiado tiempo era imposible, hoy es algo cotidiano, sumergido en lo posible más actual. Más bien, de lo que se trata en eso imposible es de una hipotética sospecha de que la realidad no está dada de antemano en ningún ámbito de lo posible, en ninguna conciencia trascendental, en ningún mundo arquetípico o ideal, en ninguna estructura ni trascendente ni 
trascendental. Si algo ocurre, si algo puede ocurrir, por primera vez, por única vez; si hay acontecimiento, ello no puede venir prefijado en ninguna estructura de posibilidad. Si algo acontece por primera vez, rompe lo posible y su acontecer, en tanto que comporte una experiencia, lo será de lo imposible.

Esto imposible se encuentra inserto en lo que acontece, en el acontecimiento, si es que lo hay, como un riguroso y abismático tal vez. El acontecimiento, si lo hay, lo que viene, évenement, no satura el porvenir; más bien está preñado de porvenir. Ese es su poderoso quizás. Roto por el quizás, se encuentra interrumpido, fracturado; lo que quiere decir también que no está completo, presente de una vez por todas. O dicho de otra manera, su acontecer está abierto al otro, a otro sentido: siempre puede tener otro sentido, siempre puede ser «otra cosa» lo que haya pasado, porque, como decíamos cuando hablábamos del texto, siempre remite a otro, a otro sentido también. Siempre hay en él, sorpresa y promesa.

Por eso su falta de completitud no es ningún trozo que le falte, nada puede saturarlo, darlo al presente. Nada posible le falta: no hay falta posible.

Ya vemos con claridad que lo imposible no es lo opuesto a lo posible, sino que más bien eso imposible no se ordena en el orden de lo posible, desordena lo posible, lo fractura. No sería un imposible negativo que formara par dialéctico con lo que hay, con lo que se encuentra presente o de cierto modo en vísperas de completitud, en demanda de totalidad. Más bien en cambio, ese imposible tiene un carácter afirmativo, moviliza, opera la posibilidad del acontecimiento, si lo hay. Lo posible contiene ya lo imposible, y aquí el verbo contener sería engañoso, y problemático. Recuerden, «el texto tiene problemas de incontinencia».

Lo que la promesa tenga de acontecimiento lo tiene a partir de esa experiencia de lo imposible, de esa deconstrucción de lo posible, de esa interrupción afirmativa y en diseminación. Pero hemos dicho que aquello que abre el sentido es un desvío del otro y hacia otro, el paso, el traspaso. Y las palabras de Fernando Rampérez vuelven a citarse con nosotros: «Todo consiste, en definitiva, en una inacabable traducción intertextual, una deconstrucción». Ese trasvase intertextual no lo es de algo definido que pasa de un lugar a otro, sino algo que se genera en su pasar, en eso "consiste todo». Un trasvase que da lugar a lo trasvasado. Pero ese trasvase ese desvío, esa traducción intertextual no puede ser la unidad identitaria de ninguna instancia original, porque pone ya la iteración, la vuelta, en el origen mismo del sentido. La letra o la escritura, la textualidad en el origen del sentido en general.

Decíamos hace un rato que no hay sentido si no es a través de aquella alteridad que viene del otro, no hay texto si no viene de otro, si no es citado de otro, si no incorpora una alteridad que fracciona su mismidad, que le fractura, le hace plural, múltiple en un fuera de sí. He aquí la iterabilidad, la instancia de repetición, de simulacro, de impropiedad en el origen mismo del sentido. De aquí una conclusión que se hace patente: repetición, o iterabilidad, no es opuesto a singularidad. Aquella imposibilidad que rompe el sentido lo hace ya repetible. 
La cita y la promesa no se contradicen. La iterabilidad, y Derrida insiste en ello, no es la repetición de lo idéntico, sino una repetición no idéntica a sí misma en virtud de esa alteridad constitutiva. La iterabilidad, el momento citacional y la promesa, la apertura del porvenir, no son incompatibles.

\section{Saquemos conclusiones:}

¿Cómo afecta todo esto a nuestro problema? Pues muy en primer lugar cambiando la coordenadas de la interrogación. Hemos pasado de esta pregunta: ¿es posible citar una promesa? Esto es, ¿es posible duplicar un acontecimiento? $¿$ Es posible transponer en otro contexto aquello que tiene lugar una vez, solo una vez, por primera y única vez? ¿Es posible citar una promesa y al tiempo mantenerla, mantener lo que de promesa tiene una promesa? Esta pregunta se ha cambiado por otra: ¿es posible no citar, no transponer cuando se hace una promesa?

Pero esta pregunta no es la simple inversión de la otra. Ahora cita y promesa han cambiado de régimen: no lo son de algo posible. Ahora citar lo es en cuanto movilización de una imposibilidad inserta en la iterabilidad de la promesa. Pues si la promesa no fuera repetible, si no fuera renovable, no habría promesa. ¿Se imaginan una promesa que al día siguiente ya no fuera renovable? Una promesa que dejara de ser promesa con el paso del tiempo, una promesa que no repitiera su acontecimiento a cada momento o en cada instante, ¿seguiría siendo promesa? Imaginen una promesa de amor que al día siguiente dice «ya no me acuerdo», la promesa de ayer no tiene hoy validez. ¿Qué promesa sería esa?

Y bien, lo que le da a la promesa su singularidad de acontecimiento es la condición iterable de esa imposibilidad. Lo se deduce de aquí es que, decíamos, se hace preciso pensar la repetición, la vuelta en el origen mismo, la cita antes del texto original. No puede pensarse el acontecimiento sin un cierto espíritu, sin una cierta dynamis, sin un cierto revenant. Fue Derrida quien nos enseñó que detrás del espíritu, de esa palabra tan usada en filosofía, Geist, hay ya un doble representacional, algo que vuelve, como un fantasma, como un reaparecido, como un revenant. Lo que viene en el acontecimiento, vuelve ya sin haber llegado, como una cita en secreto. Si no hay cita de una identidad predefinida, si el texto es siempre la promesa de sentido abierta en su letra, si en cada promesa hay ya un doble, un espíritu que vuelve, un revenant abierto a lo que viene, entonces citarse con ello es citarse con la alteridad misma del otro, con la imposibilidad que lo constituye como alteridad, y citar una promesa es citarse con la imposibilidad: un modo de experiencia de lo imposible, una deconstrucción en marcha.

Siempre que se cita, se abre una promesa de nuevo sentido, se opera con esa ingobernable imposibilidad. De esta manera, la letra del espíritu refiere a esa instancia escritural, textual, que contiene la iterabilidad de lo que viene, del arrivante, del revenant; y nuestra promesa de mantener la promesa en la cita de Fernando Rampérez moviliza esa imposibilidad y un no saber que se abre 
a situaciones imprevisibles. Si se quiere, también ese secreto, ese corte, o esa interrupción, se-cernere.

Y ojeo, mientras espero que venga a la cita, en el deseo de su voz amiga, ojeo entre sus papeles, entre los envíos de amistad que me hizo y que, en lo que yo sé, están todavía inéditos. Allí encuentro estas frases dentro de un trabajo que me envió hace tiempo bajo el título Estética y política:

Cada palabra es una cita: una nota a pie de página, la repetición de algo ya dicho; pero también una cita con el otro o con lo otro, una forma de quedar para después, el compromiso de un encuentro sin presente ni presencia que siempre quedará diferido.

Estamos a cada paso en literatura citándonos: repitiéndonos, y quedando para después. Estamos a cada paso en democracia repitiéndonos, y quedando para después, abriéndonos a un futuro incierto en el cual quizá volvamos a encontrarnos o volvamos a citarnos. Si es que no nos esperamos (en) la muerte.

Cada palabra dice, por tanto: espero, esto espero; o bien: te espero. La literatura, o la democracia, es una agenda: anotaciones de lo por hacer, de las citas por cumplir, de lo que nos falta. Enumeración del deseo, cita, repetición casi compulsiva del deseo. Casi credo.

Pero cada cita presupone también la posibilidad de la ocultación, la apertura al espacio no público, o incluso la infidelidad: citar en secreto.

Como una cita sin nota al pie, una cita encubierta que reta al lector o bien directamente le engaña; una deslealtad hacia el citado y una mentira hacia el que lee. O bien ignorancia del escribiente. U olvido. U homenaje encubierto. Una cita secreta.

No concibo la amistad sin ese homenaje encubierto y sin esa «cita secreta».

\section{Bibliografía}

Derrida J., 1975, La diseminación, Madrid, Fundamentos.

Derrida J., 1986, «Jacques Derrida: leer lo ilegible» (entrevista a Jacques Derrida realizada por Carmen González-Marín), Revista de Occidente, 62-63, p. 160-182.

Derrida J., 1998, "Comme si c'était possible, 'Within such limits'...», Revue Internationale de Philosophie, 205, p. 497-529.

Derrida J., 2006, Decir el acontecimiento, ¿es posible?, Madrid, Arena Libros.

Rampérez F., 2009, A destiempo. Sobre Proust, filosofía, literatura y otros relatos, Madrid, Biblioteca Nueva. 